\title{
LARGE SCALE MANIPULATION OF THE INTERACTIONS BETWEEN KEY ECOSYSTEM PROCESSES AT MULTIPLE SCALES: WHY AND HOW THE FALCON ARRAY OF ARTIFICIAL CATCHMENTS WAS BUILT
}

\author{
JAN FROUZ ${ }^{1,2, *}$, MARTIN BARTUŠKA ${ }^{1,2}$, JAN HOŠEK ${ }^{3}$, \\ JIŘí KUČERA ${ }^{4}$, JIŘí LEITGEB ${ }^{5}$, ZBYNĚK NOVÁK ${ }^{6}$, MARTIN ŠANDA ${ }^{7}$, \\ and TOMÁŠ VITVAR ${ }^{7}$
}

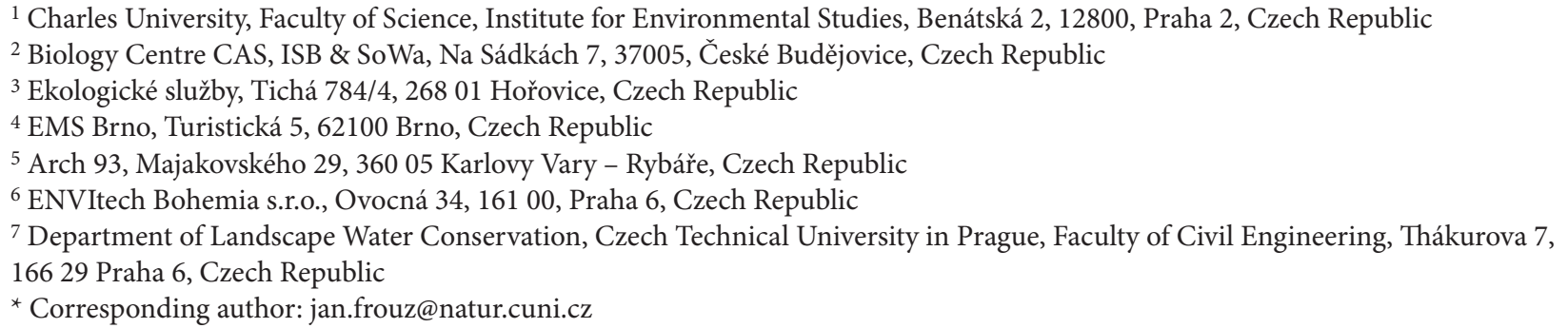

\section{ABSTRACT}

Understanding how natural processes arise from complex interactions between particular processes at small spatiotemporal scales and in turn how these processes form patterns at large spatiotemporal scales is one of the current principal questions in environmental science. The problem is very complicated, as in many cases, key processes are often studied by researchers in separate disciplines such as ecology, soil science or hydrology. One of the major obstacles is that the processes at a landscape scale are difficult to manipulate and, in many cases, even measure. In particular, the belowground processes are in many cases overlooked or at least understudied. Here we briefly describe a methodological solution used to cope with this problem and describe artificial catchments designed for experimental manipulation at the level of a landscape, called FALCON. This array has two treatments: one mimics a site reclaimed using an alder plantation and the other was left to unassisted primary succession. For each treatment, there were two replicates in four similar catchments. Individual catchments are hydrologically isolated from the environment and equipped with instruments, so that all the main processes and all significant flows of substances and energy in the ecosystem can be monitored, including the cycling of water, nutrients and gas between the ecosystem and the atmosphere. In addition, in each catchment there are sets of lysimeters, which allow the study of small-scale processes and how these can be extrapolated to the catchment scale. In addition, two lysimetric fields exist alongside the catchments for monitoring the effects of the experimental manipulation.

Keywords: carbon storage; downscaling; energy budget; runoff; soil development; upscaling; water budget

\section{Concept of large-scale manipulation experiments and how they can help us with upscaling and downscaling}

Issues of scale are present in virtually all environmental disciplines (Wu et al. 2006). While natural processes are generally driven by hotspots and transport between hotspots, they are significantly affected by particular features at several spatiotemporal scales. For example, several previous hydrological studies (e.g. Klemeš 1983; Dooge 1986; Blöschl and Sivapalan 1995; Merz et al. 2009) reveal that small-scale processes and approaches cannot be easily extrapolated to large spatiotemporal scales. Similar examples involving the dynamics of organic matter in soil (O'Rourke et al. 2015) reveal that processes at the scale of particles and aggregates may be driven by factors that are different from those driving key processes at large scales. For example, establishment of tree seedlings in rain forest depends on their interaction with pathogens at a microscale and animals that transport their seeds at the land- scape scale. The common feature of all these examples is that although processes at large scales are the product of small-scale processes, the complexity at large scales often cannot be predicted from that at small spatiotemporal scales, and in turn, processes and approaches at large scales cannot easily be downscaled. Understanding the interactions between the processes determining the overall output of major ecosystems, is therefore one of the key problems of modern environmental science. In a recent study, Blöschl et al. (2019) highlight the need to address issues of scale as one of the crucial tasks of hydrology. Similarly, scaling is an issue in various aspects of soil science (O'Rourke et al. 2015; Pachepsky and Hill 2017) ecology (Urban 2005) and many other environmental disciplines (Wu et al. 2006). Thinking about interactions between scales involves a related aspect, system boundaries. Boundaries are ubiquitous at all scales (Cadenasso et al. 2003). Large systems can often be reduced to a set of subsystems or units with natural boundaries, in respect to soil the horizons can be reduced to soil aggregates etc. 
Units defined by natural boundaries often have their own set of drivers that determine the processes in that unit, such as processes at the level of a pedon or soil aggregate, if one only considers soil (O’Rourke et al. 2015).

The complexity of processes across spatiotemporal scales also implies uncertainties in the observation and monitoring of processes. The assessment of large-scale processes is often based on several partial processes or indicators, from which the overall outcome is estimated using various statistical and modelling approaches. This is inevitable, because at some scales we cannot directly measure the whole process and instead measure the rate of a process, a sample or an indicator. These values, however, are biased not only by common measurement errors, but also by uncertainties about whether the sample or indicator includes the spatiotemporal variability of a given parameter, how well the given indicator describes the whole process or if all key processes are covered $(\mathrm{Wu}$ et al. 2006). This difficulty in determining the parameters at large scales is one of the reasons why it is difficult to make comparison across scales.

The most important way of testing hypotheses in environmental science is to use manipulation experiments. In this way, it is possible to control all key variables, keep most of them constant, and manipulate one or few. This allows the testing of a hypothesis about the effect of a particular factor. However, there is no guarantee that the factor manipulated affects the process in the real world. In contrast, formulating hypotheses based on the observation of individual factors is dependent on how they correspond with reality. However, one can never be sure if the observed pattern is not driven by interactions with factors not observed in the study. Manipulation experiments mostly involve well controlled small-scale "bottle experiments" (Kareiva 1989). Many of the basic theoretical concepts of environmental science are based on experiments done at micro and mesoscales. However, as explained earlier, upscaling from understanding at a small scale is difficult and, in many cases, hardly possible due to the great complexity at large scales. In addition, small-scale processes are often modulated in large-scale settings. That is, a particular small-scale manipulation experiment often mimics a particular large-scale setting, which limits the generality of these experiments. One way of overcoming the limitations of small-scale manipulation and the observation approach may be by using controlled manipulation experiments at a large scale (Lawton 1996) or even at a landscape scale. There are numerous manipulation experiments at large scales in the literature, for example, manipulation of patch quality and disturbance of connectivity and other properties (Jenerette and Schen 2012). While these manipulation experiments may provide some understanding of what happens at large scales, they are seldom designed to explore the interaction between processes at various spatiotemporal scales or those between various domains such as soil, vegetation etc. A way forward is a transplant experiment in which a small part of an ecosystem is placed in another context (Jenerette and Schen 2012). These experiments indicate how small-scale processes are modified at large scales.

Promising methods for exploring the interaction of processes across scales include a combination of largescale manipulation with observation, and/or manipulation of the conditions at the smallest spatiotemporal scales, as in catchment-scale manipulation experiments (Cosby et al. 1996). These experiments address the changes that occur in the whole catchment in response to experimental manipulation. This can be accompanied by detailed studies and/or manipulation experiments at small spatiotemporal scales.

As already mentioned, concept of scales is associated with boundaries (Cadenasso et al. 2003). At each spatial scale, there are parts of the system that are natural units with well-defined natural boundaries. An example of such well-defined units, which are a part of large system, are individual trees in a forest, soil aggregates in a particular soil layer or, at a landscape scale, catchments that are a natural unit of water movement in the landscape etc. On the other hand, some components of an ecosystem are more "continuous" and definition of boundaries are then somewhat arbitrary (Cadenasso et al. 2003). When experimenting, we can define the experimental unit. We may use natural units, with natural boundaries, such as individual trees, or arbitrarily set boundaries, such as an area of forest with several trees. This choice will depend on the question, method and other factors, such as the tradition of a particular field of research. This choice has many consequences. Some research questions are best addressed using individual, natural units, others using arbitrary boundaries. Moreover, individual units (trees) in a forest may be very variable. This variability is likely to mask the effect of the treatment. We may choose similar trees, but then the result applies only to trees with similar attributes. We may also study groups of trees and choose a size of group that includes a particular range of variation of the natural unit (in each group, trees will be variable, and may even include the range of variability occurring in the forest). However, at the same time, we make sure that variability of our arbitrary chosen unit (group of trees) is low. Often, we use a combination of both, natural and arbitrary boundaries; for example, we may use a natural boundary of one plant as an experimental unit, but arbitrarily define boundary by the plot in which the plant is grown. Boundaries can also be manipulated. Many landscape-scale experiments involve manipulating patch size or spatial arrangement etc. (Jenerette and Schen 2012), which is done by manipulating boundaries.

Studies of ecosystems often involve interactions between various processes, namely energy flow and the cycling of water, carbon and other nutrients, which are closely interlinked (Raffaelli 2010). Despite the close linkage of some of the key processes, for which it is easy to find 
natural units at the landscape scale, for others it is more practical to work with arbitrary units. Catchment-level experiments (Cosby et al. 1996) typically include a natural unit, the water cycle, so suspended or dissolved matter can be quantified and budgeted for. Manipulation experiments at a catchment scale are suitable, when focussing on water and nutrient budgets at the landscape scale. Manipulating natural catchments is particularly difficult, as it is impossible to replicate the experiments. This means that the natural variability within a catchment and between catchments masks the effect of the manipulation. On the other hand, studies on primary production and soil C storage in forests consisting of different species of trees may be replicated by planting blocks of different species of trees side by side in the form of a common garden experiment. This will enable, after some time, the determination of the biomass produced in individual blocks, the properties of the soil in the blocks with different species of trees, and if the initial soil conditions are known, how much of certain elements, such as soil C, was sequestered, or lost (Vesterdal et al. 1998; Frouz et al. 2013). The advantage of this approach is that it is possible to choose areas that are relatively homogeneous for planting the trees, which will result in very good statistical power, when evaluating the effect of the treatments on the target variable, such as $\mathrm{C}$ storage in plant biomass or $\mathrm{C}$ storage in soil. It may also be possible to manipulate or record what happens in these large-scale treatments, in order to determine, how it corresponds with processes at smaller spatial scales (Frouz et al. 2013). However, when linking the effect of individual treatments in common garden experiments to water movement in a landscape, direct budgeting would be extremely difficult. It would be necessary, therefore, to study individual components of the water cycle or their indirect indicators and try to upscale budgeting by modelling bearing in mind all the uncertainties, such an approach entail.

\section{Concept of manipulation experiments using artificial catchments}

Many of the drawbacks of natural catchments arise from their natural variability and/or peculiarities, which make the direct measurement of some components difficult to budget for, such as, subsurface water flow. These drawbacks can be overcome by using artificial catchments, which are built in a way that reduces spatial heterogeneity and allows a more precise budget for water at a large scale. These artificial catchments have been used for several decades to help conceptualize the runoff pathways on small hillslopes. These studies opened the way for the development of a variety of new concepts namely in hydrology and runoff, on natural or artificial hillslopes (Laine-Kaulio et al. 2014; Gabrieli and McDonnell 2018). The new generation of artificial and/or artificially managed catchments were developed to address complex processes between atmosphere, vegetation, soil and water, known as the "critical zone". The pioneering artificial catchments in this context are the Hydrohill catchment in China (Kendall et al. 2001) and the Chicken Creek catchment in Germany (Gerwin et al. 2009), which form a part of the worldwide Critical Zone Exploration Network (Lin et al. 2011; Brantley et al. 2017). The grassland hillslope Hydrohill catchment $\left(490 \mathrm{~m}^{2}\right)$ was established in order to compare the artificial Hydrohill with the adjacent natural forested micro-catchment Nandadish within the Chuzhou Hydrology Laboratory (Gu et al. 2018) and in particular to constrain the principal surface and near subsurface runoff on hillslopes (Beven 2012; van Verseveld et al. 2017). In contrast to the vegetated Hydrohill, the Chicken Creek catchment (6 ha) built in 2005 is a landscape designed to determine the initial phase of ecosystem evolution. The Chicken Creek catchment is an attempt to link various disciplines in ecology and environmental sciences, including botany, zoology, hydrology and soil science. Studies on these artificial catchments have resulted in substantial progress in the development of new concepts in hydrology, ecosystem ecology and other related fields in aspects, such as runoff, erosion or relationship between ecosystem development, water budget and other ecosystem properties.

Artificial catchments are systems that are easy to monitor, which makes it easier to determine water and solute flow. However, individual artificial catchments are nevertheless case studies similar to those on natural catchments described above. However, a combination of artificial catchments and large-scale experimental manipulations (e.g. common garden approach) can overcome this. By developing several artificial catchments in the same manner side by side, will enable treatments to be replicated (e.g., manage plots differently or plant them with different species of trees) and at the same time accurately determine all key ecosystem processes, namely energy flow and cycles of water, carbon and other nutrients. We can study the response of these processes to different treatments and at the same time, using smallscale observations or manipulation can downscale and observe mechanisms driving these processes at small spatial scales. This will enable the development of new ways of studying the connection between key ecosystem processes, such as soil C sequestration, water storage and many others.

This is similar to the various recently developed ecotrone facilities, which consist of sets of mesocosms in the form of large lysimeters. The conditions in these facilities can be manipulated, but at a much smaller scale than in open-air artificial catchments. The largest lysimeter includes shrubs or even small trees. A big advantage of these facilities is that they are highly controlled and the treatments can be replicated. A disadvantage is their relatively small size (several tens of $\mathrm{m}^{2}$ containing around 10 tons of soil) (Barry et al. 2019; Rosher et al. 2019) compared to the above-mentioned artificial catchments 
of $10^{2}-10^{4} \mathrm{~m}^{2}$. Their small size means they cannot be used for studying even small-scale landscape processes, such as runoff, erosion and sedimentation, or competition between woody species etc.

Another complementary way of quantifying landscape ecosystem processes at the scale of at least $10^{2}-10^{4} \mathrm{~m}^{2}$ is the eddy covariance method for assessing the exchange of gases $\left(\mathrm{CO}_{2}\right.$, water vapour and methane) between ecosystems and the atmosphere (Baldocchi et al. 2003). Thus, the next logical step could be a replicated manipulation experiment consisting of several adjacent artificial catchments, designed for studying the exchange of gases between ecosystems and the atmosphere.

\section{An example of application of manipulation experiments using experimental catchments}

As explained above, using hydrologically isolated artificial catchments as a unit in a large-scale manipulation experiment brings many advantages in terms of linking various ecosystem processes at large spatiotemporal scales. However, it is difficult to carry out a replicated manipulation experiment that includes more than one artificial catchment. This is because of the necessity to balance the number of units with the number of treatments and replicates. Based on the processes that should be assessed, the smallest size of an artificial catchment needs to be close to existing experimental natural catchments, which is $10^{2} \mathrm{~m}^{2}$ (Gu et al. 2018). This is sufficient for using the eddy covariance technique, in which one tower serves two neighbouring systems with the possibility of including additional units. The large size of this unit also indicates it would be useful for exploring processes at large spatial scales. Consequently, this setup will be more suitable for studies over long periods. This is even more enhanced by the complexity of the construction, during which isolating the catchment hydrologically involves excavating large quantities of soil and backfilling or dumping it elsewhere. It is therefore an advantage if the excavation and backfilling or spreading the soil mimics processes that occur in a natural catchment and can be part of the experiment. In the past, experimental sites in previously mined areas such as Chicken Creek, were used to explore the early stages in the development of an ecosystem. Because of the complexity, manipulation experiments can only include a limited number of treatments. Here we propose a meaningful scientific question that can be addressed using two treatments. In addition, we look for treatments that are similar to an existing manipulation experiment, so we can benefit from pre-existing knowledge in formulating a hypothesis. Practical applications of the results of manipulation experiments are a useful asset. The general question proposed is how the growing of $\mathrm{N}$ fixing plants affects ecosystem development differently compared to unassisted ecosystem development. As the planting of nitrogen-fixing plants is a popular reclamation strategy, this also has practical implications. Nitrogen is the most limiting nutrient in temperate ecosystems (Vitousek and Howarth 1991). This is particularly true for sites in the early stages of primary succession, including post-mining sites. That is why planting $\mathrm{N}_{2}$-fixing trees is often recommended to speed up ecosystem development (Parkinson 1978; Mikola et al. 1983). Exploring the effect of increasing nitrogen in an ecosystem is likely to result in a better understanding of the recent global shift in ecosystem behaviour that has recently resulted in an increase in the availability of nitrogen. After global climate change, the addition of nitrogen to ecosystems has resulted in is the next-largest effect of man on world ecosystems. Over the past few decades, by various measures, such as anthropogenic $\mathrm{N}$ fixation, burning of fossil fuel and promoting $\mathrm{N}$-fixing plants, man has substantially increased $\mathrm{N}$ input into ecosystems. (Vitousek and Howarth 1991) The consequences of this increased $\mathrm{N}$ input include substantially increased primary productivity, promotion of fast-growing tall species of plants, reduction of plant diversity, soil acidification, affected the mycorrhiza association and - site specifically - lower C sequestration in soil. Understanding how the addition of $\mathrm{N}$-fixing plants alters the long-term development of ecosystems, compared to unassisted primary succession is a question that relates to many key issues in ecosystem ecology, soil science and other related disciplines.

Another reason for the choice of this experimental system is that well-studied Chrono sequences of reclaimed alder plantations and unreclaimed sites are available near the experimental catchment. Open cast mines often operate for decades. During that time, they generate very similar sites of the same sort of substrate using similar technologies. These sites are ideal for studying ecosystem development using Chrono sequences. A Chrono sequence is a set of similar sites with the same trajectory of development. Extensively studied Chrono sequences are available for post mining sites, which were either reclaimed by planting alder or left to unassisted ecosystem development. These Chrono sequences reveal that sites with different $\mathrm{N}$ inputs differ substantially in terms of soil organic matter storage and soil profile development (Frouz et al. 2001; Frouz and Nováková 2005; Šourková et al 2005; Frouz and Kalčík 2006; Frouz et al. 2008; Frouz et al. 2013) (Fig. 1). These differences result from complex interactions between plant production, plant litter inputs and soil biota (Frouz et al. 2007, 2008, 2013). Sites with nitrogen-fixing plants harbour a richer soil fauna, namely more earthworms. Earthworms, due to intensive bioturbation, incorporate plant litter into soil, which results in a faster initial soil C storage and formation of the organo-mineral A horizon in the soil. In contrast, at unreclaimed sites initial soil formation is slow, earthworms are absent, soil fauna caused bioturbation is weak and most litter accumulates in a litter and fermentation (Oe) layer. It has been also reported that these interactions 


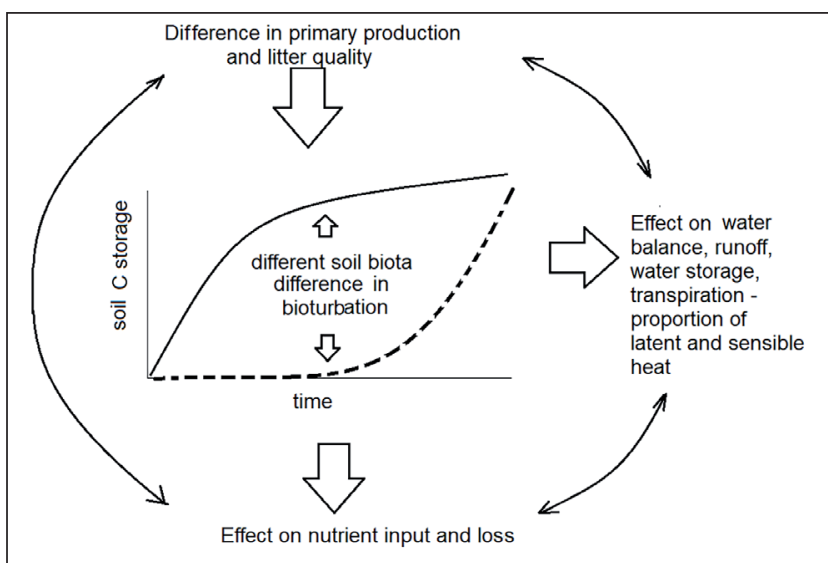

Fig. 1 Scheme of major interactions, between key ecosystem components, which will be studied using FALCON array of artificial catchments. In the middle there is schematic graph of expected dynamics of soil $C$ storage in the catchment based on previous work on chronosequences of similar sites in vicinity (Šourková et al. 2005; Frouz and Kalčík 2006). In this diagram reclaimed alder plantation are represented by solid line, unreclaimed sites with succession are represented by dashed line.

affect the development of plant communities (Frouz et al. 2008). Moreover, plants that increase the amount of organic matter in soil produce soils that have a high water field capacity and are able to store more water (Frouz 2018). At a mesoscale, it is reported that bioturbation affects soil porosity. Availability of light and nitrogen affects understory vegetation and this again affects the earthworm community (Roubíčková and Frouz 2014). In addition to soil carbon storage, earthworms affect soil conditions, nutrient availability, interaction between arbuscular mycorrhiza and ectomycorrhiza, which also affect plant communities (Frouz et al. 2008). Consequently, this model offers numerous possibilities for exploring the interaction between traits of dominant plants, soil and ecosystem carbon storage and the water budget. This triangle of interactions needs to be understood in order to be able to effectively address ongoing climate change by manipulating land use. Despite many studies of the individual linkages (Frouz et al. 2007, 2008, 2013; Cejpek et al. 2018) the complexity of interactions is largely underexplored. Moreover, this triangle of interactions is closely linked to other processes, such as plant primary production, which drives litter input, nutrient dynamics, soil biota developments etc. Because primary production and $\mathrm{C}$ storage is so different at reclaimed and unreclaimed sites (Fig. 1), it should be possible to determine the effect of different soil C sequestration on different key ecosystem properties and partition, using statistics and modelling, how individual small-scale processes contribute to large-scale patterns. Then, we will be able to manipulate them at a microscale and so test our hypothesis. We believe that the ability to link precise budgeting and detailed observation in two-contrasting treatments over time at a large scale and by small-scale experimental manipulation will help us link key ecosystem processes across scales.
These Chrono sequence studies also indicate that the observed effects at large spatiotemporal scales, such as runoff, water storage and carbon storage, are outcomes of processes that occur at the level of soil aggregates or between them, further interacting with various processes at the mesoscale. One of the key objectives of the FALCON project is therefore to understand how these small-scale processes interact and form large-scale patterns. One of the tools that should help us answer this question is a set of small lysimeters embedded in the catchment or in its buffer area. About half of them will be used for monitoring how an observation at a small-scale relates to the large-scale picture and the other half can be used for experimental manipulation. In addition, it is likely that a set of mesoscale facilities will be developed in the future for markedly manipulating key factors, such as, the traits of dominant species of trees.

\section{The experimental catchment FALCON}

\section{Site description}

The FALCON experimental catchment was established on a post-mining site near Sokolov (Czech Republic). The name Sokolov (in local language) is derived from that of a bird of prey - a falcon. It complements the Hydrohill and Chicken Creek catchments, the only two currently monitored artificial catchments worldwide. Unlike the existing experimental catchments, which were designed for particular case studies, there are two treatments in FALCON catchment that mimic a reclaimed alder plantation and unreclaimed site left to primary succession, respectively. There are two replicates of each treatment resulting in four parallel catchment plots. They are hydrologically isolated from the environment and equipped with instruments to monitor the main ecosystem processes: the cycling of water, nutrients and gas between the ecosystem and the atmosphere, that is, all the significant fluxes in the ecosystem. The parameters monitored include rainfall, surface and subsurface outflow, chemical and isotopic composition of precipitation, pore water and runoff components at a high spatial resolution. Sets of soil lysimeters in each plot will measure the small-scale water balance, which can be extrapolated to the scale of the entire experimental catchment. Two lysimetric fields are located outside the catchment area, which can be used for manipulating the rainfall regime and composition of the aggregate.

The catchment is located at a post mining site near Sokolov, Czech Republic (50.2218908N, 12.7071839E), which is part of LTER Sokolov post-mining ecosystems in an area owned by Sokolovská Uhelná, a.s. Mean annual precipitation is $650 \mathrm{~mm}$, mean annual temperature $6.8^{\circ} \mathrm{C}$ and altitude $428 \mathrm{~m}$ a.s.l. The installation is located on an inner spoil tip of overburden from the open cast mine Jiří, which consists of Miocene sediments that contain up to $70 \%$ clay, in which the dominant minerals are 
Kaolinite, Illite and Montmorillonite. The clay, however, is impregnated with carbonates (calcite and siderite) and fossil organic matter (kerogen) and in the tip forms large solid blocks (mudstones) that over time break down into smaller pieces the size of sand or gravel. Initially the clay is slightly alkaline, $\mathrm{pH} \sim 8$. The catchment area is located on a gentle slope $(\sim 0.6 \%)$ facing southwest. Previous research in this area indicates that plants grow well on this material at reclaimed sites and those left to natural succession (Frouz et al. 2001, 2008).

\section{Experimental setup}

The whole array consists of four separate catchments $40 \mathrm{~m}$ wide and $60 \mathrm{~m}$ long, located side-by-side (Fig. 2) and facing northwest with the longer axis in a southeast-northwest direction. The catchments are surrounded in the north and west by a channel that drains the individual catchments and prevents water flowing from the upper parts of the slope into the catchments. Another drainage channel prevents water inflow from the upper parts of the hill and is located on the southeast side of the area. Individual catchments include small channels that prevent surface inflow from upper parts of the catchment area. The boundary of each partial catchment is sealed by compacted clay that acts as an insulator of very low saturated hydraulic conductivity due to artificial compaction $\left(\mathrm{K}_{\mathrm{s}}=1.1 \times 10^{-10} \mathrm{~m} \mathrm{~s}^{-1}\right)$, which is $5-10 \mathrm{~cm}$ thick at the bottom and along the sides of the catchments. This pool was then backfilled with broken claystone over the sealant layer, which is initially likely to increase the hydraulic conductivity (as high as $\mathrm{K}_{\mathrm{s}}=10^{-4} \mathrm{~m} \mathrm{~s}^{-1}$ ), which will then gradually decrease over time to values typical for consolidated clays in this region $\left(\mathrm{K}_{\mathrm{s}}\right.$ at the range of $10^{-5}$ to $10^{-7} \mathrm{~m} \mathrm{~s}^{-1}$; Cejpek et al. 2018). Each catchment drains to the southwest, where there is a water gate measuring the subsurface outflow from the catchment. Surface water is collected in a concrete ditch with a water gate to measure surface runoff, which then enters the main channel by which water leaves the catchment (Fig. 2 and 3). Surface of each catchment as well as bottom of the sealing layer is shaped like an open book, being lowest close to the centre of the catchment and highest at the edges, with an inclination similar to that of the slope of the catchment. This generates a flow of surface and subsurface water towards the central part of the western edge of the catchment where the outlets for surface and subsurface water are located. For construction reasons, the deepest point for surface and subsurface water flow are not exactly above each other, but are about $3 \mathrm{~m}$ apart along the western edge.

The different stages in the construction of a catchment are visible in Fig. 4, starting with the excavation and sealing of the area, installing drainage, backfilling and reshaping ten areas, and installing a surface drainage system (Fig. 3). This enables the measuring of surface and subsurface runoff in four separate catchments. Two of the catchments were levelled and planted with alder
Table 1 Instrumentation.

\begin{tabular}{|l|l|}
\hline Parameters measured & number of units \\
\hline Surface runoff + water samples & one per catchment \\
\hline Subsurface runoff + water samples & one per catchment \\
\hline Subsurface water level and temperature & 10 per catchment \\
\hline $\begin{array}{l}\text { Soil moisture and temperature at depths } \\
\text { of } 20 \text { and } 80 \text { cm }\end{array}$ & 10 per catchment \\
\hline Observation shafts & 7 per catchment \\
\hline Vacuum ceramic cups & 5 per catchment \\
\hline Percolation lysimeters & 6 per catchment \\
\hline Bucket lysimeters & 10 per catchment \\
\hline Global radiation & one per two catchments \\
\hline Meteorological station & one per catchment \\
\hline Rainfall collector & 10 per catchment \\
\hline Eddy tower & one per two catchments \\
\hline Soil respiration multiplexor & one per two catchments \\
\hline
\end{tabular}

(c. 10000 seedlings per ha) as in other parts of the area. The other two were made to look like spoil tips and left to natural succession. The two levelled and two spoil tips are located side by side (Fig. 2) and the eddy tower is located in the northeast corner of the two catchments. The positions of the catchments and tower are arranged so that a diagonal line across the two-neighbouring catchments (i.e. two level or two curved catchments) is more than $100 \mathrm{~m}$ with over $90 \mathrm{~m}$ of target habitat facing in the direction of the prevailing wind. We modified the gap between the two catchments, so that it has the same vegetation as the catchments and will be included in eddy measurement, although not a part of the catchment per se. The equipment installed in the catchment is listed in Table 1 and its position depicted in Fig. 2. Below we describe in more detail the instrumentation that will be used to measure water flow, radiation and carbon storage and other processes in the catchments.

\section{Monitoring of key ecosystem processes}

The equipment will be used to quantify the water (and matter) fluxes (including dissolved or suspended material) between the catchments and their surroundings and simultaneously quantify the distribution and quality of the water in different parts of the catchments. The input via atmospheric deposition is measured using precipitation (rain and snow) and deposition samplers (used for determining the chemistry of solutions) and automatic rain gauges for quantifying the volume. Soil solution is sampled by three types of lysimeters.

Surface runoff is collected in shallow concrete channels that come together at the end of the catchment and discharge into a reservoir where it is measured using a Thomson type overflow weir. The water level is continually monitored by an ultrasonic sensor. The outflow is calculated using an experimentally derived rating curve (height of water level/discharge), with a measurement 


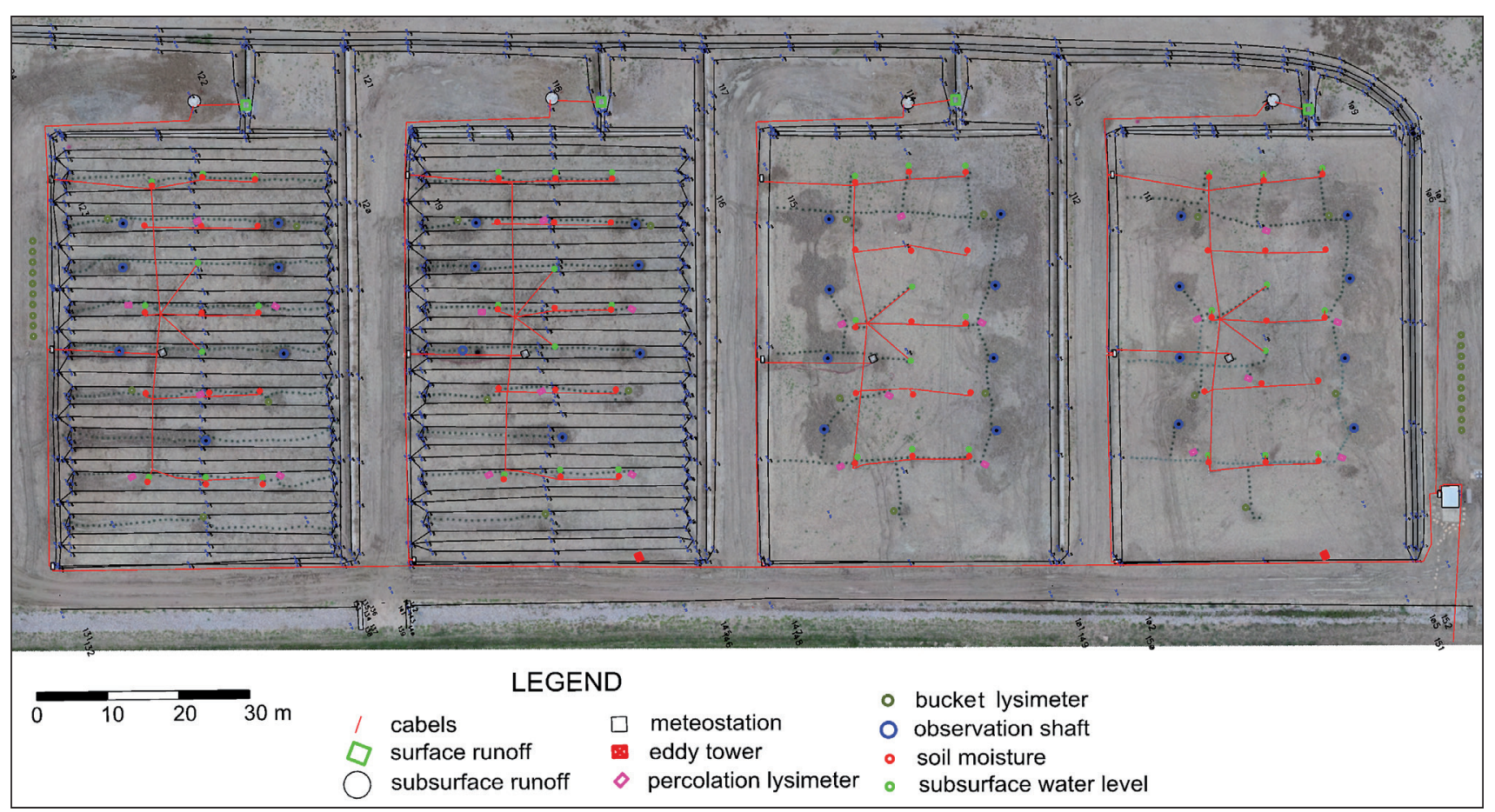

Fig. 2 Aerial photo of whole catchment array and location of instrumentation in one of the catchments.

range between 0.02 and $40 \mathrm{l} \mathrm{s}^{-1}$. The recorded measurements are stored in a local data logger and simultaneously sent to the central data store. The surface outflow is also sampled using the automatic sampler HACH AS950, which samples a volume that is proportional to the quantity of surface outflow over a particular interval of time. As there are several sample bottles it is possible to collect surface outflow over particular periods or even collect several (separate) samples for a particular period. All this equipment is located in the underground shaft next to the overflow weir.

To measure subsurface runoff, the outflow from the bottom of the catchment passes through the boundary wall of the catchment via plastic pipes to the reservoir of Thomson's weir where it is measured. The level is continually monitored by an ultrasonic sensor and the outflow calculated as above, but in this case with a measurement range of between 0.01 and $131 \mathrm{~s} \mathrm{~s}^{-1}$ and stored on the data logger. The drainage outflow is sampled by an electronically controlled solenoid valve, which collects samples at user-specified intervals, as described above by equipment in the underground shaft (Fig. 5).
Soil water measurements and sampling. Soil solution is monitored and sampled using three different types of lysimeter:

1. Gravitation lysimeters (pan type) collect water mainly from large soil pores when it is saturated following rain and snowmelt. We used flat square shaped plastic lysimeters filled with inert quartz sand, with a capture area of $471.5 \mathrm{~cm}^{2}$, which drain into an underground container in a plastic box. Depth of installation is $20 \mathrm{~cm}$.

2. Suction lysimeters collect capillary water in between soil particles. We used the approved Teflon coated quartz vacuum lysimeter Prenart. Suction cups are connected by tubing to bottles that are regularly emptied using a vacuum pump. Standard depth of installation is $20 \mathrm{~cm}$ at selected points along with a second one at a depth of $60 \mathrm{~cm}$.

3. Balance lysimeters measure different components of the soil solution by sampling it after percolating through soil with a well-defined surface area. It consists of two plastic cylindrical containers. Outer container is a watertight protective case permanently fixed in the ground. The inner container is placed inside this

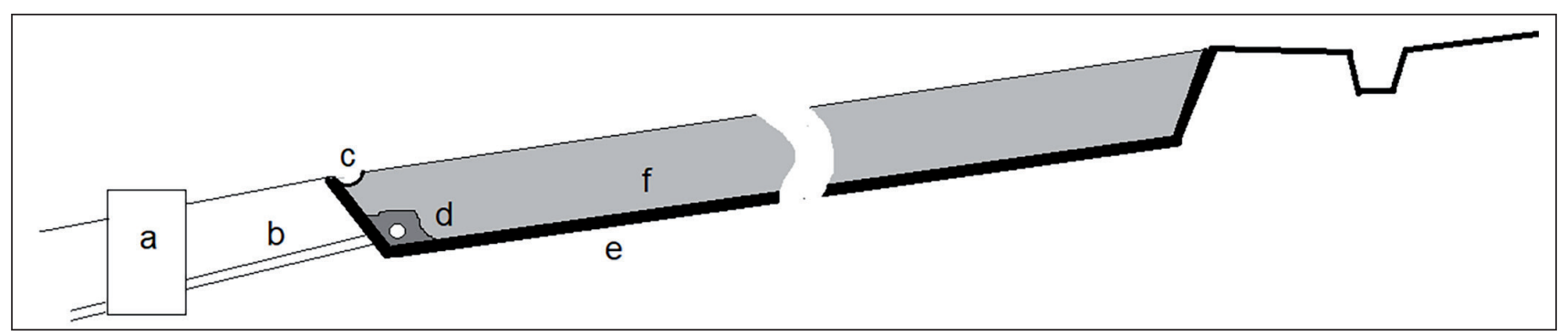

Fig. 3 Scheme of the individual catchment transection: a) measurement shaft for subsurface runoff measurement (see Fig. 4 for details), b) pipe bringing subsurface runoff from drainage system, c) surface runoff collecting ditch, d) drainage, e) clay sealing, f) backfill. 


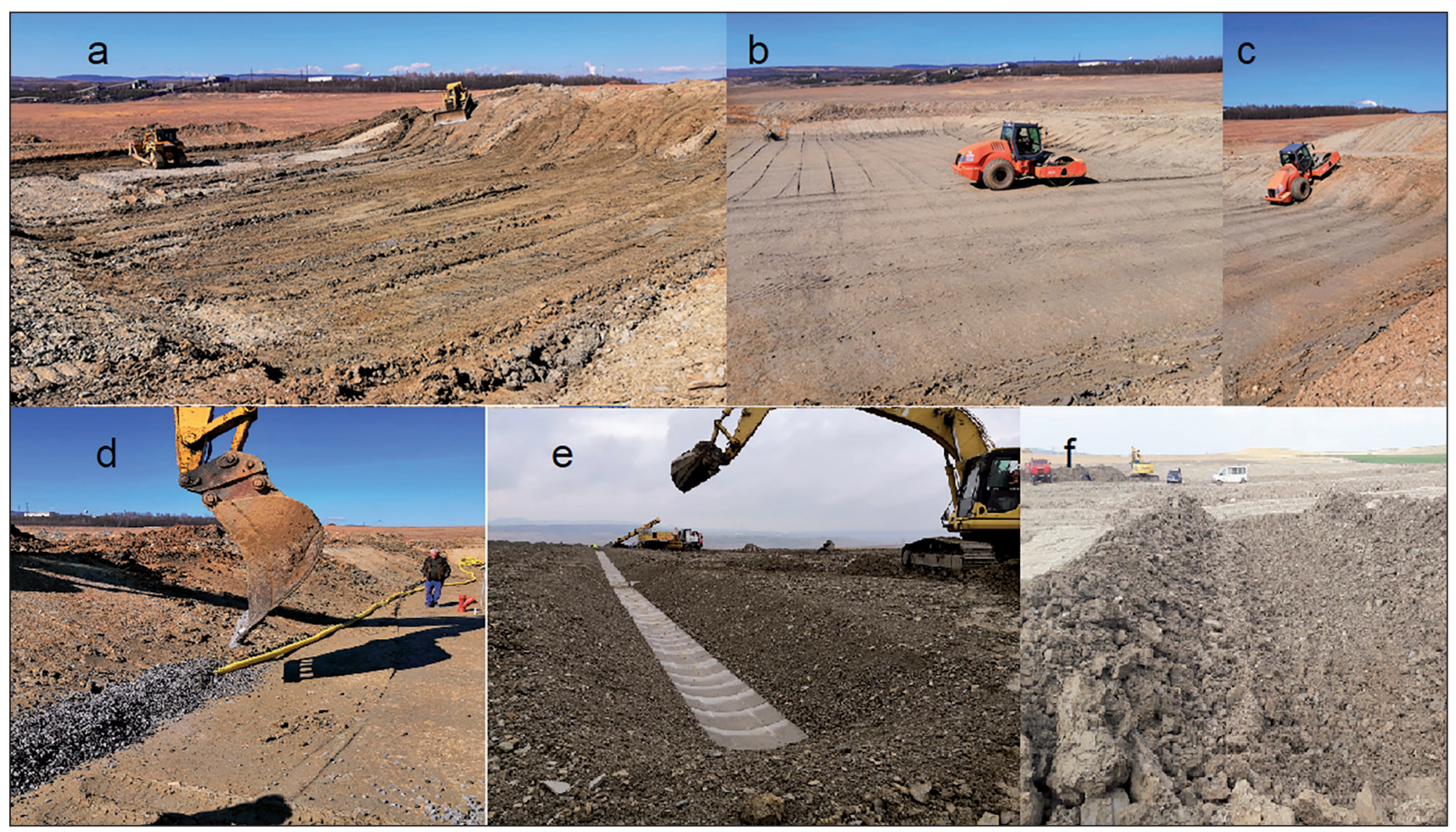

Fig. 4 Key steps of catchment construction a) excavation, b,c) construction of sealing, d) construction of drainage system, e) detail of surface runoff collecting ditch, $f$ ) overall view on finished array.

case and filled with soil. In this way, the percolating soil solution is filtered and subsequently collected and stored in the tank. The device is constructed, so that the inner container can be weighted using a portable balance and samples of the soil solution collected. The surface area of the lysimeter is $688 \mathrm{~cm}^{2}$ and the depth in the soil $60 \mathrm{~cm}$ and it can weight changes with an accuracy equivalent to a rainfall of 1 to $2 \mathrm{~mm}$. Soil
Moisture sensors (Campbell) regularly measure soil moisture at depths of 20 and $80 \mathrm{~cm}$ in grid covering the catchment (Fig. 2). Wells with a pressure transducer in a stainless-steel case regularly located in the grid covering the catchment are used for water-level measurements.

To monitor the exchange of $\mathrm{CO}_{2}$ and $\mathrm{H}_{2} \mathrm{O}$ between the catchment and surrounding atmosphere, two adja-

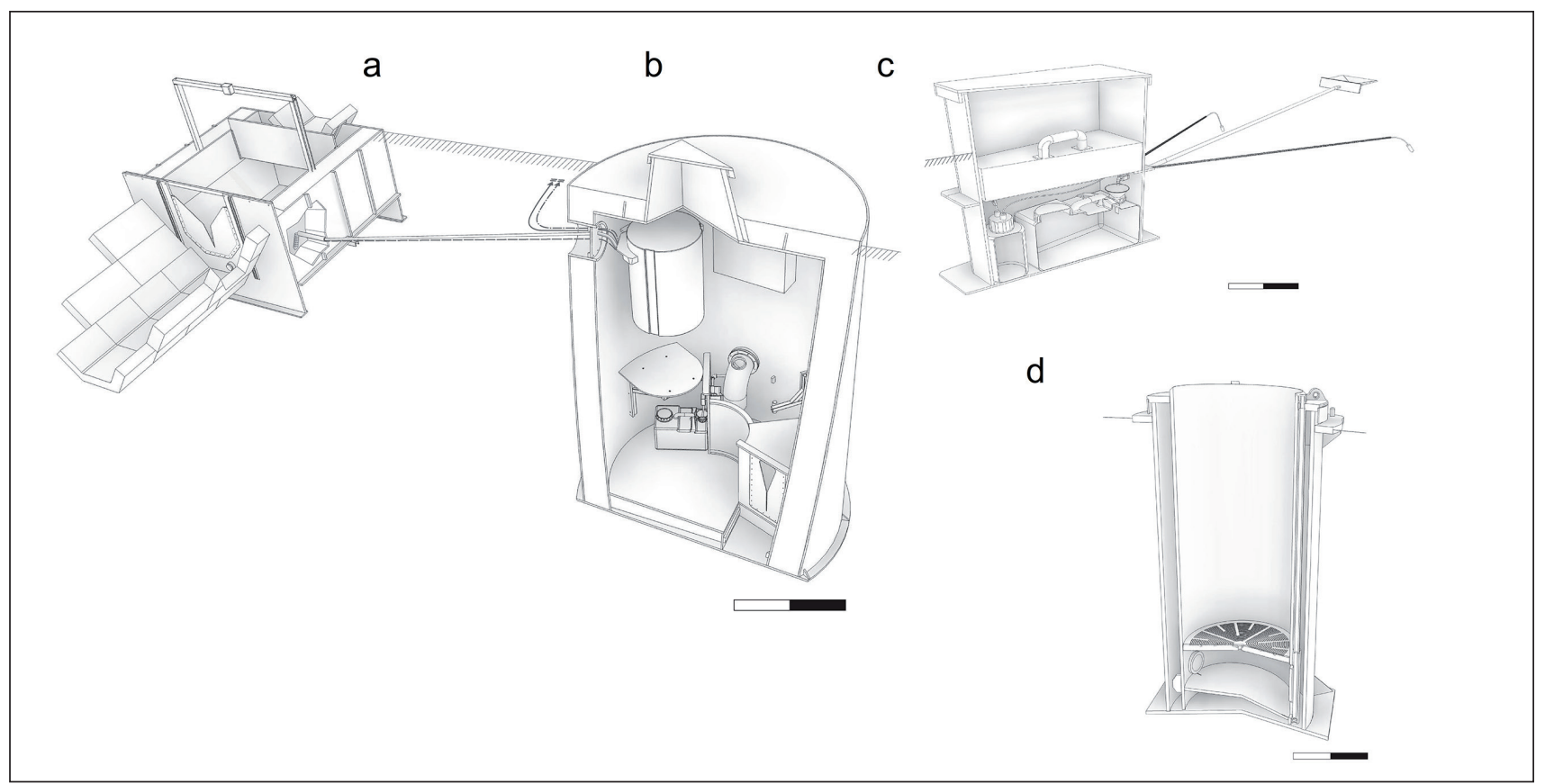

Fig. 5 Major devices used for water monitoring: a) device for surface runoff measurement, b) shaft for subsurface measurement, c) gravitation and suction lysimeters, d) balance (bucked) lysimeters. 
cent of the catchment will be grouped in pairs in order to obtain a sufficient area for eddy covariance measurements, as explained above. Based on previous experience and preliminary measurements of wind direction, the tower was positioned so that it captured the prevailing winds coming from the basin. This will allow the total $\mathrm{CO}_{2}$ exchange between the ecosystem and the atmosphere to be quantified. The eddy tower is equipped with a LI-7500DS Open Path Analyzer and Gill WindMaster anemometer. At the same time, eight fixed sites (2 in each river basin) will be installed to measure soil respiration using a LI-8100A Automated Soil Gas Flux System. Each pair of catchments is equipped with a unit for measuring total radiation and radiation balance.

In addition to equipment for monitoring water flow and gas exchange, an access shaft to a rhizotron will be located in each catchment. These are plastic shafts equipped with observation windows and predestined places, where it is possible to install additional devices. This will allow the easy and non-disturbing installation of virtually any device for monitoring soil development and nutrient flow. Each shaft is equipped with two observation windows (10 $\mathrm{cm}$ in diameter), located at depths of $0-10 \mathrm{~cm}$ and $20-30 \mathrm{~cm}$ for monitoring root growth and soil profile development. Data collected by loggers are stored in a central data depository in the catchment area, which is equipped with in-house software the universal measuring and evaluating system for environmental measurements WIN-I-MAG. The basis of which is time proven architecture for measuring and evaluating ENVItech systems, which are very reliable even under the most demanding conditions. The kernel of the system consists of a Run-time system that ensures parallel multi-tasking of several processes: measuring, archiving, processing, data export and various pictorial and printed outputs. All this is done in real time, without loss of data. Edges of each catchment are permanently marked by points that make it easier to monitor the catchment from drones using remote sensing. A network of erosion points is located in each catchment. Five permanent plots of vegetation and five neighbouring plots are available for collecting soil samples and following the development of the vegetation, soil chemical properties and soil biota.

\section{Cooperative possibilities}

This facility was built by a consortium led by the Biology Centre, which consists of Charles University, South Bohemian University and Czech Geological Survey, in addition to members of many other institutions, among which the Czech Technical University and Brandenburg Technical University are particularly noteworthy in terms of the planning and operation of the array. This facility was designed as an open access facility. Researchers who want to use the array to answer specific scientific questions, using various methods, including the use of exist- ing data, measurement of additional parameters, lysimeter experimental manipulation, modelling approaches or any other research that might benefit from the existing array are warmly welcome. Interested researchers should contact the first author of this article to discuss their particular project.

\section{Acknowledgements}

FALCON catchment was built with the support of the project EF16_013/0001782, Research of key soil-water ecosystem interactions at the SoWa Research Infrastructure, Initial monitoring of the catchment was partly supported by project 8I20001 (both awarded by Ministry of Education Youth and Sport). Catchment planning, construction and operation received significant material and logistic support from Sokolovská Uhelná a.s. coal mining company. Arch 93 atelier did excellent work in planning the technical details of the catchment array. The principal contractor of the work was ENVITECH, other key sub-contractors who contributed substantially to the success of the project were Rekultivační výstavba Most, EMS Brno and Ekologické služby.

\section{REFERENCES}

Baldocchi DD (2003) Assessing the eddy covariance technique for evaluating carbon dioxide exchange rates of ecosystems: past, present and future. Glob Chang Biol 9: 479-492.

Barry KE, Mommer L, Ruijven J, Wirth C, Wright A et al. (2019) The Future of Complementarity: Disentangling Causes from Consequences. Trends Ecol Evol 34: 167-180.

Beven K (2012) Rainfall-Runoff Modelling: The Primer. 2nd ed John Wiley and Sons, Chichester, UK.

Blöschl G, Bierkens MFP, Chambel A, Cudennec C, Destouni G, Fiori A Zhang Y (2019) Twenty-three Unsolved Problems in Hydrology (UPH): a community perspective. Hydrol Sci J 64: $1141-1158$

Blöschl G, Sivapalan M (1995) Scale issues in hydrological modeling: a review. Hydrol Process 9: 251-290, https://www.doi .org/10.1002/hyp.3360090305.

Brantley SL, McDowell WH, Dietrich WE, White TS, Kumar P, Anderson SP, Chorover J, Lohse KA, Bales RC, Richter DD, Grant G, Gaillardet J (2017) Designing a network of critical zone observatories to explore the living skin of the terrestrial Earth. Earth Surf Dyn 5: 841-860.

Cadenasso M, Pickett STA, Weathers KC, Jones CG (2003) A Framework for a Theory of Ecological Boundaries. BioScience 53: 750-758.

Cejpek J, Kuráž V, Vindušková O, Frouz J (2018) Water regime of reclaimed and unreclaimed post-mining sites. Ecohydrology 11: e1911.

Cosby BJ, Norton SA, S. Kahl JS (1996) Using a paired-catchment manipulation experiment to evaluate a catchment-scale biogeochemical model. Sci Total Environ 183: 49-66.

Dooge JC (1986) Scale problems in hydrology, Kiesel Memorial Lecture, University of Arizona, February 1986. Reprinted in: Buras (ed) Reflections in hydrology. Washington, DC, American Geophysical Union, 1997, pp 84-145. 
Frouz J (2018) Changes of Water Budget during Ecosystem Development in Post-Mining Sites at Various Spatiotemporal Scales: The Need for Controlled Systems. In: Liu J-F, Gu W-Z (eds) Hydrology of Artificial and Controlled Experiments. IntechOpen.

Frouz J, Elhottová D, Pižl V, Tajovský K, Šourková M, Picek T, Malý S (2007) The effect of litter quality and soil faunal composition on organic matter dynamics in post-mining soil: A laboratory study. Appl Soil Ecol 37: 72-80.

Frouz J, Kalčík J (2006) Accumulation of soil organic carbon in relation to other soil characteristic during spontaneous succession in non reclaimed colliery spoil heaps after brown coal mining near Sokolov (the Czech Republic). Ekologia 25: 388-397.

Frouz J, Keplin B, Pižl V, Tajovský K, Starý J, Lukešová A, Nováková A, Balík V, Háněl L, Materna J, Düker C, Chalupský J, Rusek J, Heinkele T (2001) Soil biota and upper soil layers development in two contrasting post-mining chronosequences. Ecol Eng 17: 275-284.

Frouz J, Livečková M, Albrechtová J, Chroňáková A, Cajthaml T, Pižl V, Háněl L, Starý J, Baldrian P, Lhotáková Z, Šimáčková H, Cepáková Š (2013) Is the effect of trees on soil properties mediated by soil fauna? A case study from post-mining sites. For Ecol Manage 309: 87-95.

Frouz J, Nováková A (2005) Development of soil microbial properties in topsoil layer during spontaneous succession in heaps after brown coal mining in relation to humus microstructure development. Geoderma 129: 54-64.

Frouz J, Prach K, Pižl V, Háněl L, Starý J, Tajovský K, Materna J, Balík V, Kalčík J, Řehounková K (2008) Interactions between soil development, vegetation and soil fauna during spontaneous succession in post mining sites. Eur J Soil Biol 44: 109-121.

Gabrielli CP, McDonnell JJ (2018) No direct linkage between event based runoff and groundwater recharge on the Maimai hillslope. Water Resour Res 54: 8718-8733.

Gerwin W, Raab T, Biemelt D, Bens O, Hüttl RF (2009) The artificial water catchment "Chicken Creek" as an observatory for critical zone processes and structures, Hydrol Earth Syst Sci Discuss 6: 1769-1795.

Gu WZ, Liu JF, Lin H, Lin J, Liu HW, Liao AM, Wang N, Wang WZ, Ma T, Yang N, Li GX, Zhuo P, Cai Z (2018) Why hydrological maze: The hydropedological trigger? Review of experiments at Chuzhou Hydrology Laboratory. Vadose Zone J 17: 170-174.

Jenerette D, Shen W (2012) Experimental landscape ecology. Landsc Ecol 27: 1237-1248.

Kareiva P (1989) Renewing the dialogue between theory and experiments in population ecology. In: Roughgarden J, May RM, Levin SA (eds) Perspectives in Ecological Theory, Princeton University Press, Princeton, NJ, pp 68-88.

Kendall C, McDonnell JJ, Gu W (2001) A look inside "black box" hydrograph separation models: A study at the Hydrohill artificial catchment, US-Japan Watershed Hydrology Special Issue, Hydrologic Processes 15: 1877-1902.

Klemeš V (1983) Conceptualization and scale in hydrology. J Hydrol 65: 1-23, https://www.doi.org/10.1016/0022-1694(83) 90208-1.
Laine-Kaulio H, Backnas S, Karvonen T, Koivusalo H, McDonnell JJ (2014) Lateral subsurface stormflow and solute transport in a forested Hillslope: a combined measurement and modelling approach. Water Resour Res 50: 8159-8178.

Lawton JH (1996) The Ecotron Facility at Silwood Park: The Value of "Big Bottle" Experiments. Ecology 77: 665-669.

Lin H, Hopmans JW, Richter DD (2011) Interdisciplinary sciences in a global network of critical zone observatories. Vadose Zone J 10: 781-785.

Merz R, Parajka J, Blöschl G (2009) Scale effects in conceptual hydrological modelling. Water Resour Res 45, W09405: 1-15, https://www.doi.org/10.1029/2009WR007872.

Mikola P, Uomala P, Mälkönen E (1983) Application of biological nitrogen fixation in European silviculture. Forestry Sci 9: 279-294.

O'Rourke SM, Angers DA, Holden NM, McBratney AB (2015) Soil organic carbon across scales. Glob Change Biol 21: 3561-3574.

Pachepsky Y, Hill RL (2017) Scale and scaling in soils. Geoderma 287: 4-30.

Parkinson D (1978) The restoration of soil productivity. In: Holdgate MW,Woodman MJ (eds) The Breakdown and Restoration of Ecosystems. Plenum Publishing Company, New York, pp 213-229.

Raffaelli DG (2010) Ecosystem ekology new synthesis. Cambridge University press, Cambridge.

Roscher C, Karlowsky S, Milcu A, Gessler A, Bachmann D, Jesch A, Lange M, Mellado-Vázquez P, Strecker T, Landais D, Ravel O, Buchmann N, Roy J, Gleixner G (2019) Functional composition has stronger impact than species richness on carbon gain and allocation in experimental grasslands. PLoS ONE 14: e0204715.

Roubíčková A, Frouz J (2014) Performance of the earthworm Aporrectodea caliginosa on unreclaimed spoil heaps at different successional stages. Eur J Soil Biol 65: 57-61.

Šourková M, Frouz J, Šantrůčková H (2005) Accumulation of carbon, nitrogen and phosphorus during soil formation on alder spoil heaps after brown-coal mining, near Sokolov (Czech Republic). Geoderma 124: 203-214.

Urban DL (2005) Modeling ecological proceses across scales. Ecology 86: 1996-2006.

van Verseveld W, Barnard H, Graham C, McDonnell JJ, Brooks R, Weiler M (2017) A sprinkling experiment to quantify celerity-velocity differences at the hillslope cale. Hydrol Earth Syst Sc 21: 5891-5910, https://www.doi.org/10.5194/hess-21-5891 $-2017$.

Vesterdal L, Raulund-Rasmussen K (1998) Forest floor chemistry under seven tree species along a soil fertility gradient. Can J For Res 28: 1636-1647.

Vitousek MP, Howarth RW (1991) Nitrogen limitation on land and in the sea: how can it occur? Biogeochemistry 13: 87-115.

Wu J, Jones, K, Li H, Loucks O (2006) Scaling and Uncertainty Analysis in Ecology: Methods and Applications. Springer-Verlag New York. 